\title{
How Rescher Failed to Fill the Fact/Value Gap ${ }^{1}$
}

\author{
Petr Kolář \\ Univerzita Jana Amose \\ Komenského Praha \\ Roháčova 63, 13000 Praha 3 \\ kolar.petr@ujak.cz
}

\author{
Vladimír Svoboda \\ Filosofický ústav \\ Akademie věd České Republiky \\ Jilská 1, 11000 Praha 1 \\ svobodav@flu.cas.cz
}

In his (several times reprinted) article How Wide Is the Gap Between Facts and Values? N. Rescher aspires to clarify the long-lasting discussion on the 'is-ought' ('fact-value') gap by providing a framework in which the related arguments can be perspicuously articulated. He then argues that even if the logical gap may be real, the transition from factual premises to value conclusions is smoothly mediated by trivially true value statements. We scrutinize Rescher's argumentation and show defects in the presented lines of reasoning. In particular, we argue that his tripartite division of statements (factual, evaluative, hybrid), as well as his emphasis on the role of evaluative truisms, introduce serious problems that escape Rescher's attention. We thus conclude that he failed to achieve his goals.

\section{Introduction}

If statements of astrology could be logically inferred from statements of astronomy, then a good astronomer who had mastered the rules of logical reasoning couldn't fail to put people on the right lines by 'perfectly fitting' horoscopes. If statements of mysticism could be logically derivable from statements of facts, then an incompetent mystic would either be incapable of logical reasoning or would lack sufficient empirical information. To the best of our knowledge, neither of these ideas has deserved attention as a deep logico-philosophical problem. Unlike the above cases, a question raised by considerations that are essentially similar, namely that of a (possible) inferential link between statements

1 Vladimir Svoboda's work on this paper was supported by Research Grant No. 17-15645S of the Czech Science Foundation. 
of values and statements of facts has provoked considerable philosophical discussion. The problem whether evaluative claims are (in principle) derivable from statements of facts still excites philosophers.

The philosophers involved in the interesting discussions on the 'is-ought' ('fact-value') question that flourished particularly in the 1960 's have not reached agreement. ${ }^{2}$ Both the prominent adherents of the idea that there is an unbridgeable gap between facts and values (or between 'is' expressions and 'ought' expressions) and proponents of the opinion that there is no such gap seem to continue holding their opposite convictions. This is not surprising as philosophical discussions scarcely have a clear and commonly accepted outcome, but the fact that the discussions reached a kind of deadlock may also be related to the lack of rigor that affects their shape. It is a great merit of Nicolas Rescher that he tried to put the discussions on firmer grounds by providing a rigorous framework which allows for a perspicuous formulation of the related arguments. In his article How Wide Is the Gap Between Facts and Values? ${ }^{3}$ which was originally published in 1990 , and since that time several times reprinted in various volumes, he presented quite a comprehensive discussion of the problem and presented his view. Though the paper was for the first time published in the last millennium, both the form and the content of Rescher's argumentation are still stimulating. Reflecting (even now, after all those years) upon Rescher's seminal paper thus means coming back to the roots of the modern, contemporary logic based philosophical debate on the fact-value distinction. One may be somewhat surprised to find out upon the reflection that the framework of the debate is more controversial than one would expect.

In his excellent introduction to the topic Rescher outlines the epistemological framework of the fact/value (is/ought) problem and formulates the theses he wants to substantiate. In particular, he points out that there really is a gap between facts and values and "valid inferential transition from factual premises to an evaluative conclusion" is impossible. Subsequently he claims that both value naturalism ${ }^{4}$ and value

2 For a representative sample of the discussions see Hudson (1969).

3 Rescher (1990, pp. 297-319).

4 The thesis that "value claims can (at least sometimes) be inferred from strictly factual contentions” (Ibidem, p. 297). 
reductionism ${ }^{5}$ are untenable. Adherence to these claims implies, in his view, neither a positive nor a negative answer to the question whether disagreements about value are objectively resolvable. The possibility of developing a plausible case for value objectivism ${ }^{6}$ is finally promised to be shown.

In spite of the fact that we are going to criticize Rescher's argumentation we consider his approach to be still one of the most stimulating and unusually clearly set contributions to the topic. Our aim in this paper is not only to criticize some problematic points of Rescher's argumentation, but also to point out as clearly as possible some questions that anyone who wishes to achieve the goals similar to Rescher's inevitably faces.

\section{The Gap}

\section{II.1. Basic Logical Deliberations}

Making the distinction between fact statements and value statements clear is a pre-condition of any plausible treatment of the problem. Rescher presents some intuitive deliberations concerning the distinction and argues for the thesis that besides factual statements and evaluative statements there should also be statements of some third - hybrid status.

The idea that the dichotomic fact/value (is/ought) division of natural language statements is to be replaced by a trichotomic division (fact/ hybrid/value) is not new ${ }^{7}$, but Rescher's argumentation supporting the idea is novel and interesting (though, as we are going to show, defective). Rescher tries to justify the inevitability of introducing the third (hybrid) status of expressions by presenting the following inconsistent triad of theses each of which looks plausible:

(CP) The Consequence Principle. Any statement which, even in the presence of some merely factual supplementation, has

5 The thesis that "value claims can always be reduced to (or redefined in terms of) strictly factual contentions" (Ibidem, p. 297).

6 The thesis that disagreements about values are objectively resolvable.

7 See, e.g. Johanson (1973, pp. 339-350) and von Kutschera (1977). 
an evaluative statement as a logical consequence should itself be classed as evaluative:

If $(\mathrm{P} \& \mathrm{~F}) \rightarrow \mathrm{V}$, where $\mathrm{F}$ is factual and $\mathrm{V}$ evaluative $(\mathrm{V} \in \mathrm{E})$, then $\mathrm{P} \in \mathrm{E}$.

(FFD) The Factuality of Fact Denial. If $\mathrm{F}$ is factual, then so is its negation, $\neg \mathrm{F}$.

(D) The Dichotomy Assumption. Any statement $F$ is either factual or evaluative but not both: $P$ is factual iff not- $(\mathrm{P} \in \mathrm{E}){ }^{8}$

The mutual inconsistency of the three principles is then proved using the apparatus of classical propositional logic. ${ }^{9} \mathrm{We}$ are not going to repeat here the simple proof in order to make room for the subsequent (quite similar) demonstration which directly underlies Rescher's forthcoming argument. This is the proof of inconsistency of a triad which differs from the previous one only in replacing $(\mathrm{CP})$ with the following principle:

(FC) Factuality Conservation. If $\mathrm{F}$ is factual, and $\mathrm{F}$ entails $\mathrm{P}$, then $\mathrm{P}$ is factual. ${ }^{10}$

Rescher then argues as follows:

(R) Now let it be that $\mathrm{F}$ is factual and $\mathrm{V}$ is evaluative, and consider the following course of reasoning:

1. $\quad \mathrm{F} \rightarrow(\mathrm{F} \vee \mathrm{V})$, by standard logic

2. $\quad \mathrm{F} \vee \mathrm{V}$ is factual, from (1) by Factuality Conservation

8 Rescher (1990, p. 301).

9 Ibidem, p. 302.

10 Rescher himself introduces the principle on p. 302. Both (CP) and (FC) can be accounted to represent different formulations of Hume's Thesis (the claim that there is a logical gap between 'is' and 'ought' (fact and value) statements). 
3. $\neg F$, is factual by the Factuality of Fact Denial

4. $\quad \neg \mathrm{F} \&(\mathrm{~F} \vee \mathrm{V})$ is factual, by (2), (3)

5. $\quad[\neg \mathrm{F} \&(\mathrm{~F} \vee \mathrm{V})] \rightarrow \mathrm{V}^{11}$

6. V is factual, from (4), (5) by Factuality Conservation

7. But (6) is contradictory to the supposition that $\mathrm{V}$ is evaluative by the Dichotomy Assumption ${ }^{12}$

Let us now make some basic comments on the structure and content of Rescher's argument (R). First we should notice that the principles of Factuality Conservation (FC), the Factuality of Fact Denial (FFD), and the Dichotomy Assumption (D) are metalanguage claims about statements made in the object language. Rescher avoids a formal way of expressing these principles but we shall try to do it since we need be precise in spelling out what we have in mind. Let us allow the variables $p, q, \ldots$, etc. range over the universe of statements and the predicates $F$ (for "factual"), $V$ (for "value"), and $\mathbf{\epsilon}$ (for "entails") be defined over the universe. Logical connectives can be the same as in the object language. Then we can formally capture the principles (FC), (FFD), and (D) as follows.

$$
\begin{aligned}
& \left(\mathrm{FC}^{\prime}\right) \quad \forall \mathrm{p}, \mathrm{q}((F \mathrm{p} \wedge \mathrm{\epsilon}(\mathrm{p}, \mathrm{q})) \rightarrow F \mathrm{q}) \\
& \text { (FFD') } \forall \mathrm{p}(F \mathrm{p} \rightarrow F \neg \mathrm{p}) \\
& \text { (D') } \quad \forall \mathrm{p}((F \mathrm{p} \vee V \mathrm{p}) \wedge \neg(F \mathrm{p} \wedge V \mathrm{p}))
\end{aligned}
$$

When we go through the original argument (R), the first thing to notice is step 4 where the factuality of $\neg F \&(F \vee V)$ is said to follow from

\footnotetext{
11 This step, albeit not commented by Rescher himself, is by standard propositional logic and can be easily checked by the truth-table method.

12 Ibidem, p. 302.
} 
2 and 3. It is undeniable that steps 2 and 3 play important roles in the desired inference but that is not enough. For the fact that both $\mathrm{F} \vee \mathrm{V}$ and $\neg F$ are factual entitles us to infer that so is $\neg F \&(F \vee V)$. Here Rescher clearly uses a hidden premise expressing a principle that is quite natural (though not completely unproblematic). The principle should be added to the triple (FC), (FFD), and (D). Let us state it in the following way.

(FR) Factuality Retention. If $\mathrm{F}$ and $\mathrm{G}$ are factual, then so are $\mathrm{F} \& \mathrm{G}, \mathrm{F} \rightarrow \mathrm{G}, \mathrm{F} \vee \mathrm{G}$, and $\mathrm{F} \leftrightarrow \mathrm{G}$.

Or in our notation

$\left(\mathrm{FR}^{\prime}\right) \quad \forall \mathrm{p}, \mathrm{q}((F \mathrm{p} \wedge F \mathrm{q}) \rightarrow(F(\mathrm{p} \wedge \mathrm{q}) \wedge F(\mathrm{p} \rightarrow \mathrm{q}) \wedge F(\mathrm{p} \vee \mathrm{q}) \wedge F(\mathrm{p} \leftrightarrow \mathrm{q}))$

Now it can be correctly said that in (R), 4 follows from 2 and 3 by (FR). Another thing which puzzles us about the argument (R) is the moral Rescher draws from it. It is clear that we cannot hold all the three principles in question at the same time, but which of them is to be rejected? Rescher concludes:

"Since the Dichotomy Assumption is also central to this apory (in which the consequence principle is an innocent bystander), we had best make it our target for rejection. On this basis one should then shift from a two sided fact/value dichotomy to a tripartite division of statements as factual, evaluative and hybrid. And accordingly, one would assign to $\mathrm{F} \vee \mathrm{V}$ this third, hybrid status. Fact and value are now seen as separated not by a sharp boundary line but by a broad corridor." ${ }^{13}$

The just quoted argumentation seems to be quite admissible but only until we observe that the rejected Dichotomy Assumption (D) in fact consists of two independent conditions (assumptions):

13 Ibidem, p. 302. 
(Da) Any statement is either factual or evaluative: $\forall \mathrm{p}(F \mathrm{p} \vee V \mathrm{p})$

(Db) There is no statement that is (at the same time) both factual and evaluative:

$\forall \mathrm{p} \neg(F \mathrm{p} \& V \mathrm{p})$

Taking this distinction into account we can easily see that it is only (Db) which is responsible for the contradiction finally reached in the proof cited. So if there is something which is to be abandoned it is obviously (Db). But as we know, Rescher rejects (D) as a whole and surprisingly in the following text we can notice that he still holds the critical (Db) as being valid.

The questionable character of the argument which leads to rejecting the Dichotomy Assumption is underlined by the fact, that the Factuality Conservation principle (which is "an innocent bystander of the apory") has to be, in consequence of the first rejection, amended too. Rescher replaces it by the following principle:

\section{$\left(\mathrm{FC}^{*}\right)$ Modified Factuality Conservation. If $P$ is logically deri- vable from factual statement, then $P$ is not evaluative.}

We have already observed that it is just (Db), the second conjunct of (D') on which the argument (R) relies. Thus concluding that the Dichotomy Assumption is to be rejected on the grounds of (R) seems to be fair. But since it is clearly only (Db) which calls for rejection but not (Da), formally there is nothing to prevent us from abandoning (Db) while retaining (Da). This would amount to admitting the idea that some statements could be of both factual and evaluative status (at the same time). However, adoption of this position is obviously irreconcilable with Rescher's 'paradigm' since if we rejected (Db) we would break down the presupposed conceptual incompatibility of being factual and being evaluative which underlies the present fact/value debate.

Rescher does not explicitly make the above move and that is why his strategy to escape the result of (R) seems to be a kind of juggling. He says 
explicitly that (D) has to be rejected. But instead of focusing on the real culprit of the contradiction, viz. (Db), he rejects (Da) while modifying (FC) to the Modified Factuality Conservation Principle, (FC*). In place of the Dichotomy Assumption, (D), he introduces "a tripartite division of statements as factual, value, and hybrid" (p.302). Let us put this new (Trichotomy) principle in the following form (where $\mathrm{H}$ is for 'hybrid'):

$$
\forall \mathrm{p}((V \mathrm{p} \vee F \mathrm{p} \vee H \mathrm{p}) \wedge \neg(V \mathrm{p} \wedge F \mathrm{p}) \wedge \neg(V \mathrm{p} \wedge H \mathrm{p}) \wedge \neg(F \mathrm{p} \wedge H \mathrm{p}))
$$

It is easily seen that ( $\mathrm{T}^{\prime}$ ) implies (Db). Thus the culprit of the contradiction in (R) has remained while the conclusion of (R) was evaded. Now, it is clear that the reason why the conclusion of $(\mathrm{R})$ was evaded is neither the introduction the Trichotomy Principle, nor modifying (FC) to (FC*) alone. The genuine reason is that in addition to these "one would assign to $\mathrm{F} \vee \mathrm{V}$ this third, hybrid status", as Rescher puts it. Let us spell out this important assumption as yet another principle we shall refer to.

(HI) Hybridity Introduction. If $\mathrm{F}$ is factual and $\mathrm{V}$ evaluative then $(\mathrm{F} \vee \mathrm{V})$ is hybrid.

The formal counterpart of (HI) in our notation is

(HI') $\forall \mathrm{p}, \mathrm{q}((F \mathrm{p} \wedge V \mathrm{q}) \rightarrow H(\mathrm{p} \vee \mathrm{q}))$

Then it is clear that - provided (T') is valid - (HI) contradicts (FC), and introducing ( $\left.\mathrm{FC}^{*}\right)$ is inevitable. This, nevertheleSs, shows that (FC) was responsible for the contradiction in (R) no less than (D). Finally, let us remark that the following statement (which we shall employ in a while) is a direct consequence of (FFD), (HI), and the trivial identity $(\neg p \vee q) \leftrightarrow$ $(\mathrm{p} \rightarrow \mathrm{q})^{14}$ : if $\mathrm{p}$ is factual and $\mathrm{q}$ is evaluative then $(\mathrm{p} \rightarrow \mathrm{q})$ is hybrid. In our notation,

14 We make use of the hardly disputable assumption: If $(\neg p \vee q)$ is hybrid, then so is $(p \rightarrow q)$. Nevertheless, the more general thesis whereby every pair of logically equivalent statements should share the status (F, V, or H) does not hold within the Rescherian approach we accept here. Such examples can be easily found. For instance, if $V \mathrm{p}$ and $F \mathrm{q}$, then $H((\mathrm{p} \vee(\mathrm{q} \vee \neg \mathrm{q}))$ despite the logical equivalence of $\mathrm{p}$ and $(\mathrm{p} \vee(\mathrm{q} \vee \neg \mathrm{q}))$. 


\section{(1) $\forall \mathrm{p}, \mathrm{q}((F \mathrm{p} \wedge V \mathrm{q}) \rightarrow H(\mathrm{p} \rightarrow \mathrm{q}))$}

So much is inherent in Rescher's line of argumentation.

We have seen that Rescher's argumentation leading to the introduction of the hybrid status of statements is obscure. Moreover, there remain a lot of open questions concerning the hybrid status of certain kind of statements. We only know that they stand between facts and values and that the propositional calculus compounds of factual and evaluative statements are of this status. We are not given any guidance that would help us to recognize the status of various important kinds of expressions. Let us consider statements corresponding to compound expressions of the first order calculus mixing factual and evaluative predicates. Is e.g. the sentence Everyone who is responsible for assassination has done something wrong to be regarded as hybrid or evaluative?

Moreover there can be doubts about the status of some expressions. E.g. $(\mathrm{V} \vee \neg \mathrm{V})$ seems to be evaluative according to the outlined classification but it is obviously entailed by any factual premise and so it should be factual according to $\left(\mathrm{FC}^{*}\right)$. On the other hand, if $\neg \mathrm{V}$ were considered as factual or hybrid, $(\mathrm{V} \vee \neg \mathrm{V})$ should be classified as hybrid. For example: $A$ is good or $A$ is not good. ${ }^{15}$

The confusion we must face while trying to find out the status to be ascribed to various kinds of expressions can be illustrated by the following example. Rescher explicitly adduces as value or "clearly value" statements like

(2) Dogs are likeable.

(3) What generally knowledgeable people like, deserves to be liked.

Nevertheless, his text itself gives us some clues that make the above status ascription disputable. Let us concentrate on the simpler case (2)

15 The extremely interesting question whether for value statements there holds some counterpart of (FFD), say The Evaluativeness of Value Denial is completely omitted in Rescher's article. 
only. Given the standard approach to the logical analysis of natural language within the first-order predicate calculus the logical form of (2) is
(4)
$\forall \mathrm{x}(D \mathrm{x} \rightarrow L \mathrm{x})$

where $D$ stands for (being a) dog and $L$ stands for (being) likeable. Since according to Rescher (2) is evaluative then, unless a very subtle argument is given in favour of the opposite thesis, there is no reason to suppose that the instances of the general statement are of some different status. Let $\alpha$ be an individual taken from a suitable universe. Then $D \alpha$ is clearly factual and $L \alpha$ is (intuitively, in Rescher's sense) evaluative. But $D \alpha \rightarrow L \alpha$ must be hybrid by (1) which in turn is a direct consequence of (HI), a principle which underlies Rescher's reasoning. The same considerations apply, mutatis mutandis, to cases like (3).

\section{II.2. On Preferential Value Subjectivism}

We have already mentioned Rescher's claim that value reductionism is untenable. He supports this thesis in section 4 of the examined article where he tries to undermine the position of preferential value subjectivism, i.e. the opinion that value statements can be reduced to (factual) claims about emotional reactions of people, their likes and dislikes, preferences or desires.

What can confuse the reader is the striking terminological inconsistency between the opening section of Rescher's article and section 4. In the first section, value subjectivism (characterized as the opinion that "evaluative questions are never objectively resolvable") is strictly contraposed to value reductionism. ${ }^{16}$ Three sections later we are surprised to find out that value subjectivism (specified as preferential value subjectivism) is treated as a kind of value reductionism. This point calls for explanation. On Rescher's view,

16 Because if value issues are reducible to strictly factual contentions and these are objectively resolvable (Rescher obviously takes this view), then evaluative questions are obviously objectively resolvable too. 
"what people happen to prefer (like, etc.) is clearly a factual matter to be settled either directly, by asking them, or indirectly, by monitoring their behavior in choice situations" ${ }^{17}$.

That is why the position that reduces value issues to people's subjective preferences counts as objectivism.

Therefore we carefully distinguish between value subjectivism and preferential value subjectivism (PVS) from now on. The latter position is by no means to be considered as a specific kind of the former one.

Let us put the terminological questions aside now and concentrate on the argument against value reductionism. Surprisingly enough the crucial argument against the criticized position denominated as preferential value subjectivism consists in pointing out that

"... there is no unproblematic way of crossing the inferential gap from You (or I or most or all of us) like (prefer, approve of) such and such to the conclusion that the item at issue is of value (is right or good or beneficial or the like)."18

A number of arguments can certainly be found against this kind of reductionism but if

“'to be of value' is (by definition) to be taken as tantamount to 'to be preferred [...] by some (particular) group or category of persons"'19

then there obviously is no space for any 'inferential gap' simply due to the supposed definitional identity of preference statements and value statements. ${ }^{20}$

Another question that arises is whether the valid inferences leading from factual claims about people's preferences (and the reductionist's definitions) to value claims are to be considered as genuine instances of reduction of value claims to factual claims. Rescher himself is not con-

17 Ibidem, p. 304.

18 Ibidem, p. 305.

19 Ibidem.

20 D. Mitchell expressed a similar opinion concerning the moral discourse: "I have claimed that one could argue validly from non-moral premises to a moral conclusion if one of the premises was a reductive definition of moral terms.” See Mitchell (1968, pp. 543-549). 
sistent at this point. On the one hand, in the beginning of the section on preferential value subjectivism he says that

"any such position [i.e. the position of preferential value subjectivism] will, of course, straightforwardly reduce evaluative claims to factual issues, since what people happen to prefer (like, etc.) is clearly a factual matter ...”.

On the other hand, at the end of the very same section he claims that any definition determining the subjectivist's conception of values has an evaluative status and "that prevents the value-subjectivism at issue from achieving any reductive ends".

Let us try to clarify the confusion with two comments:

First - we think that Rescher is right when he classes preferential value subjectivism as reductionism (no matter whether the definition in question is endowed with evaluative or factual status). For it is difficult to imagine any theory in which evaluative claims would be reduced ('factualized') in more straightforward way. So preferential value subjectivism does reduce values to facts.

Second - Rescher's conclusion about the failure of PVS to reach reductive ends is not right, even if we accepted the strange concept of reductionism under which the value-subjectivism at issue is prevented from achieving any reductive ends. His classifying the definition in question as evaluative is groundless. Any definition of this kind strives to explicate some term. (The definition in question is analytic.) The suggested explication can be correct or incorrect, but be the definition correct, wide, narrow, or completely off the point ${ }^{21}$, it consists just in explicating the particular term. The term explicated (e.g. 'good' or 'valuable') is mentioned, not used in the definition. The paradigmatic formulation of such a definition is 'The term $A$ means (stands for) the same as the term(s) $B$ '. And we do not see how such a definition could be included in

21 Naturally, to judge about the appropriateness of any definition concerning the terms of moral discourse is a tricky matter. We can even doubt whether any definition whatsoever can capture the actual role of the given expression in our language. 
the family of evaluative statements, since it is evaluative no more than the statement The word 'good' consists of four letters.

The section 5 of Rescher's article is devoted to criticism of Value Consequentialism i.e. the opinion that value claims can be reduced to facts "through holding that 'to be of value' is (by definition) to be taken as tantamount to: 'to produce consequences of type $\mathrm{T}$ for many (or most or all) people" ${ }_{22}$. As before, it seems that Rescher's argumentation misses the point while concentrating on an attempt to demonstrate that value consequentialism is not able to justify any inference from factual premises to evaluative conclusion. The value consequentialist who considers the definition: 'A is wrong (bad) iff A produces (has as an consequence) pain' as representing an exhaustive explication of the notion of wrongness is obviously able to show that factual statement Extracting my tooth produces pain implies evaluative statement Extracting my tooth is wrong. What is to be attacked is not the trivial inference due to the definition, but the very definition which is obviously insufficient and incompatible with our intuitions concerning the notion of wrongness.

We would misrepresent Rescher if we suggested that he is not aware of the just hinted deficiency of such definitions. He does present a criticism of the insufficiency of definitions submitted by consequentialism, but surprisingly this is not his major concern.

\section{II.3. On Value Subjectivism}

Reflecting on Rescher's aim to defeat the doctrine of value subjectivism we can see a straightforward way to achieve the goal. Consider the following argument.

First, let us accept together with Rescher the thesis that fact and value statements differ in kind. (Here, the real nature of the distinction is irrelevant.)

Second, let us make the assumption that both fact and value statements can in principle feature in place of arguments of logical operations, where logical operations stands for classical logical connectives. 
This assumption plays an essential role in Rescher's considerations, as witnessed by his presupposing that expressions like $\mathrm{F} \rightarrow(\mathrm{F} \vee \mathrm{V})$ or $((\mathrm{F} \vee \mathrm{V}) \& \neg \mathrm{F}) \rightarrow \mathrm{V}$, where $\mathrm{F}$ and $\mathrm{V}$ stand for fact and value statements, respectively, appear as premises of a wholly unproblematic classical argument.

And third, let us take the objectivist's view of truth, whereby a statement's possessing a particular truth value (or lacking any) is objective matter, independent of our beliefs, desires, feelings, etc. as opposed to relativism or subjectivism about truth. Even if nothing in the article discussed entitles us to attribute this view to Rescher directly, let us make the assumption that the fact objectivist (the one who endorses the thesis that "factual questions are always objectively resolvable - at least in principle", as Rescher puts it) would endorse truth objectivism as well. Then it follows from the three premises that value subjectivism is false.

The reasoning behind the above argument is this. If value statements can enter the process of classical logical derivation and/or can be spoken of as objects of logical entailment (as Rescher does) they have to be assigned truth values. This is so because the very concept of (standard) logical entailment is defined in terms of truth (truth values). And since possessing a particular truth value (or lacking any) is objective, there is no room for the thesis that value questions are never objectively resolvable (value subjectivism). If sound, this argument shows the direct way from truth objectivism to value objectivism.

We can see the following objection to the argument just presented. Why should we step on the thin ice of allowing value statements as objects of logical entailment construed semantically? Cannot we simply resort to the syntactic concept of derivation instead and keep the premises while not being forced to accepting the conclusion? Of course, we could do that. Such an enterprise would, nevertheless, require constructing a deductive system with formulae being built up of the expressions of two categories (say, F and V - recall the first assumption above). The system would also include axioms and/or rules allowing some transformations of the formulae. But unless a suitable semantics is given to the system we obviously don't know that the system codifies some inferences between factual and value statements and excludes the others. And after 
the semantics is given it is the concept of entailment which comes to play. Unless this is employed in some non-standard way the truth objectivist must face the argument.

What moral can be drawn from such a line of reasoning? It seems to us that if a truth objectivist wishes to discuss the appropriateness of value subjectivism without falling into triviality he should reconsider the second premise of the argument just presented. But denying truth values to value statements can, in turn, cast new light on the very formulation of the fact-value inferential gap problem and any related problem in which the notion of a value statement and the notion of (classical) logical entailment are employed together. And in such a light it is not difficult to come to the radical but most natural conclusion that G.H. von Wright made about the problem of derivability of prescriptive statements from descriptive ones and which can mutatis mutandis be applied to the present topic:

"Logical consequence is a truth-preserving relationship. [...] Since prescriptions are neither true nor false they can figure neither as premises nor as conclusions in logically valid inferences." ${ }^{23}$

\section{The Filling}

Speaking of the 'filling' of the inferential gap ${ }^{24}$ between facts and values within Rescher's approach might seem rather odd since he explicitly concludes that "the negative upshot of a quest for 'genuinely evaluative' conclusions entailed by 'strictly factual' premises should occasion no surprise" as it is just the non-inferability of the statements which is to be considered as an appropriate explication of what is to be a "value statement'. "The crucial point is that the value realm is inferentially closed.

23 von Wright (1985, pp. 268-269).

24 There are two readings of the term 'gap' that are implicit in Rescher's treatment. Accordingly, two ways to fill the gap can be considered. On one reading, the gap is conceived as an inferential gap between facts and values. It can be filled or bridged by means of value truisms. On the other reading, the gap is conceived as, say, a conceptual one that can be filled by hybrid statements. In this and the subsequent section we shall concentrate on 'filling the gap' in the former sense. 
One cannot enter it inferentially from without." ${ }^{25}$ Thus Rescher acknowledges the existence of the gap. Moreover, his way of upholding the old idea ascribed to Hume is quite surprising as it seems to be rather at odds with what has been shown before, namely that evaluative conclusions can be derived from statements of some third (hybrid) status (possibly mixed with statements of facts). As hybrid statements are obviously not considered as equipped with both evaluative and factual status (and they naturally do not have the evaluative status only), they can be conceived of as representing the Trojan horse allowing us to enter the 'fortified' realm of values.

Rescher's intention is not to defend the very existence of the gap but to support the thesis that the actual existence of the gap between facts and values is not enough to discredit value objectivism. For this purpose he introduces the concept of evaluative truism. Such truisms, according to Rescher, represent the inferential mediators between facts and values. Although they belong to the value realm they can be spoken of as filling the gap.

"The salient fact is that in innumerable situations, the transition from factual premisses to value conclusions is mediated by (frequently enthymematic) value premisses that are essentially trivial and truistic." 26

Rescher gives us the following example. He suggests that though the inference:

(5) Doing A would cause Smith needless (pointless) distress

Therefore: It would be wrong for me (or anyone) to do A

is not valid, it can be turned into a valid inference when enriched by the following "assuredly available" enthymematic premise:

It is wrong to do something that causes people needles (pointless, unnecessary) pain.

25 Rescher (1990, p. 310).

26 Ibidem. 
This statement is said to represent a truism which could be dissented from only by those who don't have any real grasp on what it is to be morally wrong. ${ }^{27}$ Such is the way the gap can be "filled". Thus value truisms pave the way to the desired bridging principle that validates the reasoning about values while enabling us to keep the difference between facts and values and not falling into value subjectivism. Since they are truisms their role in the inferences is not determined by their being recognized or accepted by any particular group of people, hence they are free of the burden of value subjectivism. And since they are evaluative they can, when added to a set of factual premises, mediate the inferential transition from facts to values.

Nevertheless, the example can hardly be accepted as the "plausible case for value objectivism" that Rescher wishes to develop. For the thesis that is to be vindicated is obviously present in the presuppositions of Rescher's approach. There are obviously at least two assumptions implicit in his argument: 1. There exists some objective notion of being wrong. (If we don't suppose that there is an objective concept of 'what is wrong' then it makes no sense to speak about someone's having a 'real grasp' on it.) 2. People are generally (normally) capable to have an adequate (real) grasp on this notion (or at least on its fundamental traits). They are authorized for example to say which type of morality is a perverse one.

It is a simple matter to demonstrate the appropriateness of value objectivism on the basis of such assumptions. But the question is whether we are allowed to accept these assumptions. To do so in such an ingenuous way as Rescher does seems to be a kind of shift from the level of philosophical inquiry to the level of commonsense reasoning.

Moreover, though we do not suppose ourselves to hold any deviant concept of morality we do not find the enthymematic premise in question to be trivial and acceptable without any proviso. For example: When I by accident step on foot of a person who suddenly crossed my way (and hence I cause her pain), I don't feel myself like doing something (morally) wrong. Similarly, when someone pinches himself

27 Ibidem, p. 311. 
pointlessly (though perhaps deliberately) and causes in this way unnecessary (mild) pain, we would not regard him to have done a wrong thing.

The 'truism' formulated by Rescher may be said to be simplified for the sake of clarity. But that's just the problem of moral discourse - any statement that would be enough comprehensive to be safe from presenting any counterexamples (supposing that one can be formulated) would necessarily turn to be so complicated that it would lose the required triviality.

\section{A Gap in the Filling}

Rescher's claims about the importance of the trivial (truistic) evaluative statements that should act as inferential mediators between facts and values, if taken literally, have some implications that open another possible attack on his argument. The enthymematic premise of argument (5) lies, according to Rescher, at the same level of trivial truthfulness as the truism of meaning which states that knives have blades. Thus Rescher's value truisms can be considered as kind of analytic statements. Knives have blades and It is wrong to do something that causes people needless (pointless, unnecessary) pain are statements of the same kind: someone who does not assent to the latter is considered as not having the concept of being morally wrong just like the one who does not assent to the former is considered as not having the concept of a knife. Now if Rescher is right in this point we can make the following observation: the (analytic, trivially valid) statement that it is wrong to do something that causes people needless pain is entailed by any statement just like the (analytic, trivially valid) statement that knives have blades is entailed by any statement..$^{28}$ And the same goes for any other value truism.

Bearing this in mind we can construct an argument showing that the Rescherian concept of a value truism is self-defeating. The argument goes as follows (a,b are constants replacing statements, and p, q again range over statements).

28 Recall the standard definition of the relation of of entailent: A conclusion is entailed by the premises iff it is impossible that all the premises are true and the conclusion is false. 
(6) 1. Fa

2.There are value truisms.

3. Let $b$ be a value truism.

Then clearly $V \mathrm{~b}$.

4. $\forall \mathrm{p}, \mathrm{q}((F \mathrm{p} \wedge \mathbf{C}(\mathrm{p}, \mathrm{q})) \rightarrow \neg V \mathrm{q})$

5. $\mathbf{E}(\mathrm{a}, \mathrm{b})$

6. $\neg V \mathrm{~b}$ assumption

Rescher's claim

from 2

$\left(\mathrm{FC}^{*}\right)$

from 2 (since $b$ is

a truism)

from 1 and 5 by 4

\section{6 contradicts 3 .}

The argument shows this: Since any value truism would be entailed by any factual statement there cannot be any value truisms (by $\left.\left(\mathrm{FC}^{*}\right)^{29}\right)$. Thus the concept of a value truism is self-defeating within Rescher's system, for we used only premises which Rescher explicitly or implicitly endorses plus the trivial thesis saying that a 'truism' (i.e. analytic statement) is entailed by an arbitrary statement.

We can only conjecture the way the argument (6) could be attacked from the Rescherian position. Nevertheless, we can see three possible ways to escape the conclusion or cast doubt upon the whole argument. First, the notorious obscurity that surrounds the concepts of analyticity

29 Formalizing $\left(\mathrm{FC}^{*}\right)$ in terms of the entailment relation as in step 4 above is justified by the following consideration. Rescher's employing the term 'logical derivation' in stating ( $\left.\mathrm{FC}^{*}\right)$ might suggest that it is the syntactical relation of consequence rather than the semantic relation of entailment that plays the crucial role in ( $\left.\mathrm{FC}^{*}\right)$. Nevertheless, a closer look reveals that this cannot be the case. First, Rescher's approach is clearly semantic. Secondly, Rescher freely mixes up the two concepts (derivation and entailment) even when stating the same principle twice (e.g. the principle of Factuality Conservation on p. 302). And finally, even if the difference had been considered significant, the deduction theorem would justify the shift from the former concept to the latter one in our argument. 
and truism could be appealed to in an argument showing that the thesis of the inferability of an analytic statement from an arbitrary statement does not hold for Rescher's 'value truisms'. Thus step 5 in (6) would be doubted. Secondly, the argument (6) could be blocked by denying the evaluative status to analytic statements. Such a strategy could follow (and broaden) e.g. the spirit of Johanson's treatment whereby logically true (i.e. not all analytic) statements are not 'purely normative'30. Nonetheless, this way seems to be obstructed by Rescher's concept of a value truism which requires that the analytic statements in question be evaluative. And thirdly, a Rescherian could object that any inference that has an analytic statement (including the 'value truisms') as its conclusion should be neglected on the grounds of its being a 'degenerate case'. Thereby step 5 of the argument would lose its legitimacy.

Rescher explicitly adduces only the case when "the factual pair $\mathrm{F}, \neg \mathrm{F}$ yields $\mathrm{V}$ via the principle ex contradictione quodlibet" ${ }^{11}$ as an example of a 'degenerate case'. Now an obvious question arises whether the inferences that have Rescherian value truisms as their conclusions should be considered as degenerate cases, too. If so, Rescher would not have to accept argument (6). (Of course, he would have to justify this classification.). If not, argument (6) still applies. The question is certainly difficult to settle but the least we can do is to reason in the following way.

Textual clues make it quite clear that Rescher accepts the degenerate cases like $\mathrm{F} \wedge \neg \mathrm{F} \mid=\mathrm{V}$ as permissible (i.e. not excluded or forbidden), and obviously valid, inferences. So what makes such inferences degenerate? The explanation which seems to be the most likely is that being degenerate' applies to a valid inference iff the inference is necessarily unsound due to its containing a contradictory premise. But this is obviously not the case with an inference that has consistent and possibly true premises and an analytic statement as the conclusion. Thus we have on the one hand the degenerate inferences whereby a value statement is (correctly) inferred from factual ones at the cost of the necessary unsoundness of the argument, and on the other hand sound arguments

30 Johanson (1973). Johanson's descriptive/normative distinction has essentially the same nature as Rescher's factual/evaluative distinction.

31 Rescher (1990, p. 303). 
whereby a value statement is (correctly) inferred from factual ones due to the analyticity of the conclusion. There seems to be no reason to consider the latter to be of the same (degenerate) kind as the former. Thus in our view, nothing in the strategy Rescher envisages gives any support to dismissing the argument (6) by means of subsuming the inference in question under the 'degenerate' cases.

The considerations presented hitherto are in our view serious enough to cast doubt on Rescher's argument brought to support value objectivism. But even when we put them aside, there remains at least one problematic point in the argument presented to show the easiness of the step across the fact/value gap. The alleged factual border on which we stand before making the step is represented by premise whose factual status is dubious. The key place in the statement Doing A would cause Smith needless (pointless) distress is the use of the notion of needless (pointless) distress. Does this notion really belong into the 'factual realm'? Whether some distress is or is not needles cannot be decided without regard to the relevant context. Let us consider two examples: Cutting a leg off represents obviously a pointless distress if the leg is sound or only slightly bruised, but it is not pointless if the leg is seized with gangrene. Similarly, a very good practical joke may justify a very slight distress (to provide the required 'point'), but it is not a reason for causing any serious distress.

Whether the distress caused by some action is justified by the goal of the action or is needless cannot be decided only on the grounds of factual analysis. It is just the process of the evaluative comparison of seriousness of the distress and the importance of the goal what enables us to decide whether the distress is pointless. Hence the statement in question can hardly be said to be purely factual.

Perhaps someone could wish to involve a notion of absolute 'needlessness' and 'pointlessness' defined as a total absence of (the agent's) reasons for acting in a certain way. But we don't believe that such a strange notion is what Rescher had in mind when formulating his argument. 


\section{Values and the Truth}

At the end of his article Rescher examines three distinctively different sorts of value realism (i.e. the position to which he refers to as to value objectivism at the beginning):

1. Alethic realism: Do evaluative contentions fall into range of assertions characterizable as true or false?

2. Property realism: Do the ascription of value to things of certain sorts (acts or artifacts, say) attribute objective (and thus evidentiable - perhaps even "observable"?) properties to those items?

3. Warrant realism: Can evaluative contentions be supported by rationally cogent considerations which, by duly legitimating such contentions, can justify people in maintaining them? ${ }^{32}$

Surprisingly in what follows no word is said in support of Alethic realism. Instead Rescher says that

"for present purposes nothing hinges on the specific appraisal categories true/false. [...] Appraisal in the range of 'correct/incorrect', 'appropriate/inappropriate', 'right/wrong' is altogether sufficient, the truth issue as such need not arise." 33

This striking shift is not accompanied with any comment explaining whether all the hitherto arguments treated consequently in terms of truth and falsity are to be considered as surmounted by the present considerations or persist being held. We can only guess that the author does not present them only to show a 'blind alley' of reasoning about values but presumes that they remain valid. Unfortunately, we cannot see any

32 Ibidem, p. 313.

33 Ibidem. 
firm ground for admitting such a presumption. Neither correctness nor appropriateness belong among well-established notions of logical discourse (at least used in the way suggested by Rescher) and their logical 'behavior' probably do not perfectly imitate that of truth.

As one of the best known experts in the area of non-classical logics Rescher is certainly aware of the various intricacies of nonstandard semantics. So we should look for a reason why he omits to discuss the apparent logical problems connected with an attempt to build semantics based on notions of correctness, appropriateness etc.

It seems that, in his view, the sphere of rational considerations exceeds not only the realm of true or false statements but extends beyond any sphere of ratiocination that can be controlled by some logical theory. If this conjecture is right there should be identifiable some relation among the expressions of a language or their senses that deserves to be called rational or even inferential but cannot be (not only in principle) explicated as a formal relation. In other words, there are arguments or inferences that are 'valid' but their validity cannot be authorized, by any logical theory.

\section{Conclusions}

Let us take stock. Rescher primarily aims at

(Aim 1) defending the doctrine of value objectivism or at least showing that

"a plausible case can actually be developed for value objectivism”.

As the inherent logical relations among the doctrines at stake show, such an aim could be achieved in a very straightforward way, namely by accepting both of the theses of value reductionism and fact objectivism. For the two theses taken together imply the denial of value subjectivism (as the only alternative to value objectivism). However, Rescher claims this route is closed, since value reductionism is a hopeless position. The route Rescher takes to rejecting value reductionism goes through 
(Aim 2) defeating the doctrine of value naturalism (which is logically weaker than that of value reductionism).

The ultimate goal of Rescher's article is then (Aim 1) given that (Aim 2) is accomplished: that is, the 'logically most pleasant' way to (Aim 1) is blocked. For this purpose, Rescher

(Contention 1) Presents an argument, (R), to the effect that a dichotomic division of statements into factual and evaluative ones is not adequate, but a tripartition of statements according to their status (factual, evaluative, or hybrid) is in place;

(Contention 2) Rejects two main kinds of value reductionism, namely preferential value subjectivism and value consequentialism;

(Contention 3) Reveals the role of evaluative truisms that act as inferential mediators between facts and values without being subjectivist.

The above considerations lead Rescher to

(Contention 4) Uphold (a particular form of) Hume's thesis while being able to explain how reasoning about values is validated on objective grounds.

Finally, in A Postscript on Value Realism he (among other things)

(Contention 5) Recognizes the issue of alethic value realism as irrelevant to the present discussion.

In spite of our having some (partial) sympathy for the theses Rescher wishes to advocate, we have presented some arguments that we believe not only to show Rescher's arguments insufficient in some points and 
untenable in some others, but also to throw some light on the general foundations of any attempt to deal with the fact-value quandary on logical grounds. In particular, we argued that:

(Obj 1) The moral Rescher draws from argument (R) is not to cogently solve what it is supposed to; the way he introduces the concept of a hybrid expression allows for incompatible status ascriptions to a statement, and, taken together with other principles Rescher explicitly or implicitly accepts, undermines his effort to sustain the separation thesis (thus shaking (Contention 1));

(Obj 2) The main arguments brought to discredit the two reductionistic doctrines (conceived to cast doubt on the possibility of inferential transition from facts to values) miss the point as the reductive definitions cross the alleged gap without difficulties (thus shaking (Contention 2)). Moreover, rejecting two particular forms of value reductionism surely does not amount to accomplishing (Aim 2);

(Obj 3) The concept of an evaluative truism is at best obscure and at worst logically self-defeating; moreover Rescher's central example of a value truism is debatable in itself (thus shaking (Contention 3)).

The above objections, if sound, put doubts upon the Rescherian pathway to (Contention 4). And finally, if (Contention 5) is to be taken seriously then a short argument can be given to the effect that Hume's thesis does not hold, at least as long as the spirit of the present debate is maintained. We offer the argument in the Coda.

\section{Coda}

Finally we would like to turn your attention to an inference that seems to undermine the thesis about impossibility to derive evaluative conclu- 
sion from factual premises provided that the framework suggested by Rescher is accepted.

(7) Whatever $x$ says is true.

$\mathrm{x}$ says that $\mathrm{A}$ is good.

$\therefore \mathrm{A}$ is good.

If we wished to preserve the previously attacked doctrine, we could perhaps submit the second premise as plausibly looking candidate for a hybrid statement. But on the one hand, we don't know enough about 'hybrid' statements to be able to classify it as one. On the other hand, whether someone pronounces some statement or not seems to be quite easily verifiable and so has the right to be regarded as a factual statement.

As the conclusion of (7) is undoubtedly evaluative the only chance for those who wish to protect $\left(\mathrm{FC}^{*}\right)$ consists in casting doubt on factual character of the first premise. But we are not able to imagine sound argumentation proving that the premise is of hybrid or even evaluative status. This inference indicates where the core of the problem lies. It is hidden in ascribing truth values to value statements.

\section{Bibliography}

Hudson, W. D., ed. (1969): The Is-Ought Question, A Collection of Papers on the Central Problem in Moral Philosophy. Macmillan and Co. Ltd. London.

Johanson, A. A. (1973): "A Proof of Hume's Separation Thesis Based on a Formal System for Descriptive and Normative Statements." Theory and Decision 3 (4): 339-350.

von Kutschera, F. (1977): "Das Humesche Gesetz." Grazer Philosophische Studien 4: 1-14.

Mitchell, D. (1968): "Must We Talk about “Is" and "Ought”?" Mind 77 (308): 543-549.

Rescher, N. (1990): "How Wide Is the Gap Between Facts and Values?" Philosophy and Phenomenological Research, 50 (Supple- 
ment): 297-319. Reprinted in the following volumes: Rescher, N., Baffling Phenomena: and other studies in the philosophy of knowledge and valuation, Rowman \& Littlefield Publishers, 1991. Rescher, N., A System of Pragmatic Idealism, Volume II: The Validity of Values, A Normative Theory of Evaluative Rationality, Princeton University Press, 1993. Rescher, N., Studies in Value Theory, Ontos Verlag, 2006. Rescher, N., A System of Pragmatic Idealism, Volume II: The Validity of Values, a Normative Theory of Evaluative Rationality, Princeton University Press, 2014.

von Wright, G. H. (1985): “Is and Ought." In Man, Law and Modern Forms of Life, eds. E. Bulygin et al., D. Reidel, Dordrecht, s. 268-269

\section{Abstrakt \\ Jak Rescher nedokázal zaplnit mezeru mezi fakty a hodnotami}

Ve svém (několikrát přetištěném) článku Jak široká je mezera mezi fakty a hodnotami? se N. Rescher snaží projasnit dlouhotrvající diskusi o mezeře/propasti mezi fakty a hodnotami (tvrzeními o tom ,co je‘ a o tom, ,co má být') a nabídnout rámec $\mathrm{v}$ němž mohou být relevantní argumenty jasněji artikulovány. Následně argumentuje, že i když zmíněná mezera může být reálná, přechod od faktických premis $\mathrm{k}$ hodnotovým závěrům je hladce zprostředkován triviálně pravdivými hodnotovými tvrzeními. V článku rozebíráme Rescherovu argumentaci a poukazujeme na nedostatky v postupu jeho usuzování. Ukazujeme zejména, že jeho rozčlenění tvrzení na faktická, hodnotová a hybridní, podobně jako jeho důraz na roli hodnotových truismů, přináší vážné problémy, které unikly Rescherově pozornosti. Docházíme tak k závěru, že nenaplnil cíle, které chtěl ve své studii dosáhnout.

Kolář, P., Svoboda, V. (2018): „How Rescher Failed to Fill the Fact/Value Gap“ Filosofie dnes 10(1): 4-30. Dostupné z www.filosofiednes.ff.uhk.cz 